\title{
The effects of intergranular carbides on the grain boundary oxidation and cracking in a cold-worked Alloy 600
}

\author{
Zhao Shen*, Judith Dohr, Sergio Lozano-Perez \\ Department of Materials, University of Oxford, Parks Road, OX1 3PH Oxford, UK \\ Corresponding author: zhao.shen@materials.ox.ac.uk
}

\begin{abstract}
Intergranular oxidation occurred in a cold-worked Alloy 600 after exposure to pressurized water reactor primary water. Micromechanical testing was conducted to study the process of intergranular cracking under the external loading. High-resolution analytical electron microscopy was conducted to characterize the microstructure and chemistry of the oxidized grain boundaries before and after the micromechanical testing. The matrix around the intergranular carbides was preferentially oxidized and $\mathrm{Cr}$ in the intergranular carbides diffused out to facilitate the formation of $\mathrm{Cr}$-rich oxide. Cracks preferentially propagated along the oxide-matrix interfaces during the micromechanical tests. Intergranular carbides are assumed to increase cracking resistance after cold-working.
\end{abstract}

Key words: Alloy 600; Intergranular carbide; Cold work; Stress corrosion cracking; transmission electron microscopy.

\section{Introduction}

Alloy 600 is frequently reported to have high stress corrosion cracking (SCC) susceptibility in pressurized water reactor (PWR) primary water over the past decades [1-7]. Domian et al. [8] were the first to develop a method for increasing the SCC resistance of Alloy 600 by thermal treatment. The authors found that the microstructure of Alloy 600 varied with different thermal treatments and that specimens exhibiting significant intergranular carbide (IC) precipitation generally showed much higher SCC resistance than those with a lower IC density in $343^{\circ} \mathrm{C}$ high purity water. Specifically, mill-annealed (MA) or solution-annealed (SA) alloys exhibited higher SCC susceptibility than thermally-treated (TT) alloys due to a lower IC coverage [8-10]. Subsequent research revealed that a semi-continuous network of ICs can also reduce SCC susceptibility effectively in hydrogenated steam environments $[6,7,11,12-21]$.

Although the beneficial effect introduced by the thermal treatment in Alloy 600 has been extensively verified through constant extension rate testing (CERT), U-bend testing, and crack growth rate (CGR) testing $[8-10,17,18]$, the mechanistic understanding of this phenomenon is still unclear due to difficulties in achieving the necessary experimental scale of analysis (micro-to-nano). To date, the role of Cr-rich ICs in SCC has been intensively studied and many possible mechanisms have been proposed [2, 4, 14, 19-21]. Thomas et al. [14] and Was et al. [19] proposed that Cr could diffuse out from the ICs and facilitate the formation of a more protective Cr-rich oxide surrounding ICs, resulting in a reduced intergranular oxidation rate and CGR. Persaud et al. [20] suggested that the ICs could inhibit the inward diffusion of oxygen by working as oxygen traps and consequently decrease SCC susceptibility. Bruemmer et al. [21] supposed that ICs could promote crack tip blunting and thus decrease CGR. Dugdale et al. [2] assumed that crack propagation could be altered by ICs from straight paths into a tortuous paths following the carbide-metal interfaces. A curved path would not only increase the total crack length but also decrease the effective stress loaded at the crack tip, resulting in the decrease of CGR observed [19].

Although many mechanisms were proposed to explain the retardation effect introduced by ICs over the past decades, they mainly focused on the materials without cold-working [7, 14-16, 19-33]. 
However, since cold-working in the structural materials used in PWRs is nearly unavoidable during manufacturing and installation, the effect of cold working has to be taken into account. Studies on the effect of ICs on SCC susceptibility within cold-worked Alloy 600 have rarely been reported in literature and a high-resolution study is needed to elucidate its effect on SCC.

The objective of the current study is to investigate the microstructure and chemistry surrounding ICs in a cold-worked Alloy 600 after oxidation and micromechanical testing through high-resolution characterization. With the results obtained in this study, a better understanding of the effect of ICs on grain boundary oxidation and cracking of Alloy 600 after cold-working has been obtained.

\section{Experimental}

The Alloy 600 sample material used in this study was provided by Institute of Nuclear Safety Systems (INSS), Japan [34]. The material was mill-annealed for 30 minutes at $930{ }^{\circ} \mathrm{C}$ and water-cooled. The IC coverage was estimated through measuring the length ratio of ICs in 20 high-angle grain boundaries based on 2D surface images. Since the IC coverages at different grain boundaries are different, the IC coverages measured at these grain boundaries were averaged. The average IC coverage was $\sim 30 \%$. Cold-work of the specimen was performed through uni-directional rolling at room temperature to a thickness reduction of $20 \%$ : also referred to as $20 \%$ cold-work. The $20 \%$ cold-work is used to simulate the working condition of the structural materials used in PWRs. Since the level of cold-work in practical application is below $20 \%$, the conditions used in this study are still accelerated compared to the level of cold-work expected in plants. The Alloy 600 has a chemical composition of $0.06 \mathrm{C}, 0.33$ $\mathrm{Si}, 0.03 \mathrm{Cu}, 0.35 \mathrm{Mn}, 0.006 \mathrm{P}, 0.001 \mathrm{~S}, 16.02 \mathrm{Cr}, 6.94 \mathrm{Fe}$, and balance Ni (wt. \%).

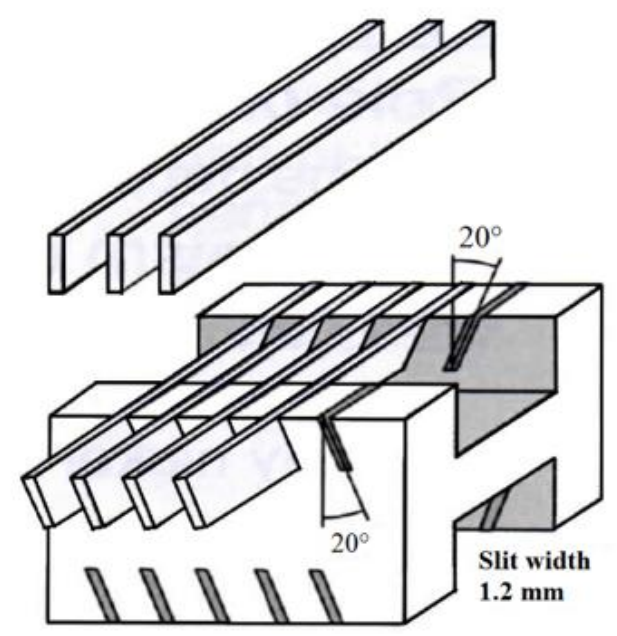

Fig. 1. Demonstration of the special jig design used to apply stress to the Alloy 600 coupon during oxidation testing.

To study the microstructure and chemistry of the oxidized grain boundaries, the Alloy 600 coupon was placed under stress by applying $40^{\circ}$ twists via a specially designed jig (see Fig. 1) while being exposed to the simulated PWR primary water $\left(500 \mathrm{ppm} \mathrm{B}+2 \mathrm{ppm} \mathrm{Li}+30 \mathrm{ml} \mathrm{H}_{2} / \mathrm{kg}\right.$ water $)$ at $340^{\circ} \mathrm{C}$ for $2000 \mathrm{~h}$. The specially designed jig was used to load stress at the coupon during the oxidation in order to accelerate the oxidation rate. Although we did not calculate the stress on the sample, it is assumed to be below the yield strength of the Alloy 600 since no cracks were observed after 2000h exposure. More details about this exposure test can be found in [35]. To understand how ICs affect the intergranular cracking after oxidation, micromechanical testing was conducted on the oxidized grain boundaries containing ICs. Due to the technical difficulties, the micromechanical testing was conducted at room 
temperature instead of at $340^{\circ} \mathrm{C}$. These preliminary results obtained at room temperature can still provide insights in the understanding of intergranular cracking at high-temperature. More details about this micromechanical testing can be found in [35].

Site-specific transmission electron microscopy (TEM) samples used in this study were all prepared via focused ion beam (FIB). The thickness of the TEM foils was around $50 \mathrm{~nm}$. More details regarding the FIB sample preparation can be found in [36]. High angle annular dark field (HAADF) and middle angle annular dark field (MAADF) imaging and electron energy loss spectroscopy (EELS) were conducted on TEM samples with a JEOL ARM200F (cold-field emission gun) operating at $200 \mathrm{kV}$ and equipped with a Gatan Quantum image filter spectrometer. The annular angular ranges used for HAADF and MAADF imaging were 73-236 mrad and 33-51 mrad, respectively. The convergence and collection half-angles for EELS were 31 and $41 \mathrm{mrad}$, respectively. Transmission Kikuchi diffraction (TKD) was performed to reveal the crystal orientations and local plastic deformation around ICs using a Zeiss Crossbeam 540 FEG-SEM equipped with an Oxford Instrument electron back-scattered diffraction (EBSD) Nordlys Max 3 detector. The step size was set to $10 \mathrm{~nm}$. More details about the TKD analysis can be found in [25, 37].

\section{Results}

\subsection{Characterization of grain boundaries prior to oxidation}

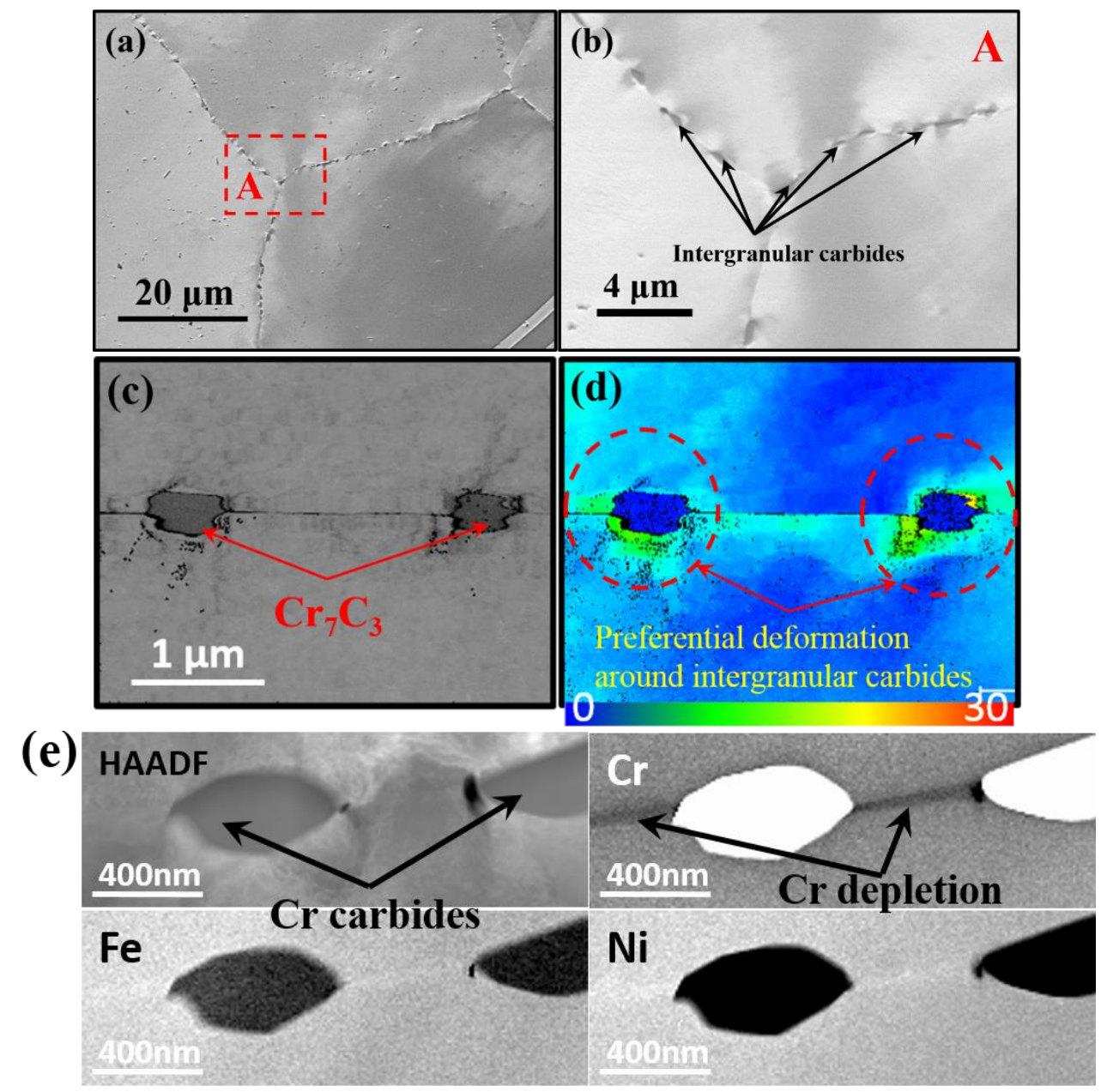

Fig. 2. (a) Secondary electron microscopy (SEM) image showing the distribution of ICs; (b) magnified image showing the ICs. TKD analysis showing the preferential deformation around ICs: 
(c) pattern quality map; (d) MO map. (e) HAADF image and related EELS elemental maps showing the intergranular $\mathrm{Cr}$ depletion ( $\sim 10 \%$ at. vs. $\sim 18 \%$ at. in matrix).

The average IC coverage in the Alloy 600 used in this study was around 30\%. TKD was conducted around the ICs prior to oxidation. Fig. $2 \mathrm{c}$ shows the pattern quality map and the electron backscattered patterns revealed that the ICs were $\mathrm{Cr}_{7} \mathrm{C}_{3}$. In the misorientation (MO) map, each pixel represented the MO value in this pixel with regard to the average MO value of all pixels in the same grain. A color temperature scale, ranging from blue (low) to red (high), was adopted to describe the different MO values. A higher MO value qualitatively represent a greater extent of localized deformation. Regions with higher MO value appeared brighter (green, yellow, and red) than regions with low MO value (blue). Fig. $2 \mathrm{~d}$ shows the MO value in the region around the ICs was higher than the other region, suggesting that the deformation is preferentially accumulated around the ICs. The accumulated plastic deformation was supposed to be caused by the cold-working since the hardness of carbides is higher than the metal matrix, which would prevent slips across the grain boundaries during plastic deformation and result in dislocation accumulation around the ICs [17]. The chemical composition around ICs was also examined with EELS. Fig. 2e shows grain boundary Cr-depletion at the regions without ICs ( 10\%at. vs. $\sim 18 \%$ at. in matrix) and no obvious Cr-depletion was detected in the matrix surrounding the ICs.

\subsection{Characterization of grain boundaries after oxidation}

Four TEM foils containing random oxidized grain boundaries and ICs were prepared after the corrosion test. Intergranular oxidation in these samples was always observed to terminate around ICs. The morphology and chemistry of the oxidized grain boundaries were analysed by HAADF and EELS respectively. The HAADF image in Fig. 3a shows two ICs at the examined grain boundary. The upper IC is more closed to the specimen surface and appears to have dissolved as a consequence of the oxidation, with the matrix around it also oxidising extensively. The intergranular oxidation was not terminated at the upper carbide and further propagated along the grain boundary until meeting the bottom IC. Once the intergranular oxidation met the bottom carbide, it started to oxidize the matrix around the IC and formed a thick oxide at the top of the bottom carbide, instead of further propagating along the grain boundary into a deeper region. The EELS elemental qualitative maps (signal counts) in Fig. 3a shows that the oxide around the upper carbide was enriched in $\mathrm{Cr}$ and $\mathrm{Fe}$, and depleted in $\mathrm{Ni}$. The formation of Cr-rich oxide around the IC was consistent to the results reported in the literature $[7,14,38]$, although the oxide observed in this study was much thicker than those reported in the literature. The signal intensities of $\mathrm{Fe}$ and $\mathrm{Ni}$ in the oxide were nearly uniform while there was a $\mathrm{Cr}$ composition gradient in the oxide, decreasing from the original matrix-carbide interface towards the matrix. EELS line-scan was conducted to quantitatively show the chemical composition across the oxide and carbide (see Fig. 3b). A Cr composition gradient within the oxide was also detected. In addition, $\mathrm{O}$ was observed around the edge of the IC, with a depth of 20-70 nm. Further observation reveals that both $\mathrm{Fe}$ and $\mathrm{Ni}$ were observed in this region. If the $\mathrm{O}$ observed in this region is due to the oxygen penetration into the IC, Fe and Ni should not exist since the ICs were composed of $\mathrm{Cr}_{7} \mathrm{C}_{3}$. As a result, this part of oxygen was supposed to be caused by the overlap between the IC and surrounding oxide but not due to oxygen penetration into the IC. The oxide at the top of the bottom IC was mainly composed of $\mathrm{Cr}$ and $\mathrm{O}$, which was very likely to be $\mathrm{Cr}_{2} \mathrm{O}_{3}$, and both $\mathrm{Fe}$ and $\mathrm{Ni}$ were severely depleted. The different chemical composition of the oxides formed around the bottom and upper carbides might be due to the different oxidation time since, when compared with $\mathrm{Fe}$ and $\mathrm{Ni}, \mathrm{Cr}$ has higher oxygen affinity, oxidizing first and forming $\mathrm{Cr}_{2} \mathrm{O}_{3}$ [39]. With further increase of exposure time, $\mathrm{Fe}$ and $\mathrm{Ni}$ would start to oxidize and form $\mathrm{Fe}-\mathrm{Cr}-\mathrm{Ni}$ oxides (similar to the oxide surround the upper carbide). 
Another interesting point is that the oxide along the grain boundary without ICs seemed not to be continuous in $2 \mathrm{D}$. The image with higher resolution reveals that the IC-free grain boundary was also oxidized, although the extent was much lower than surrounding the ICs (see Fig. 3a).
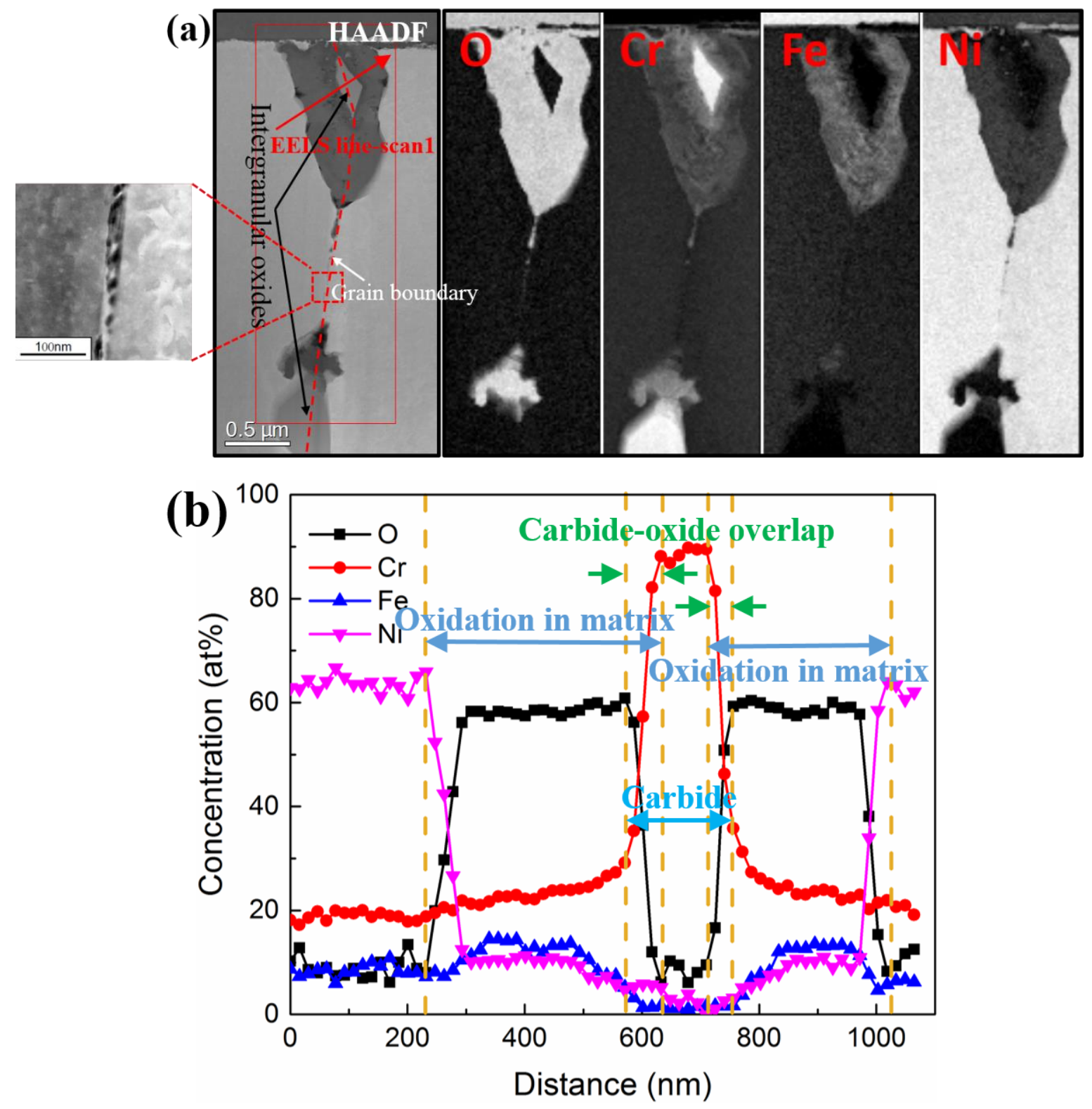

Fig. 3. (a) HAADF image with indication to the EELS line-scan1 location and related EELS elemental qualitative maps; (b) quantitative EELS line-scan across the IC.

\subsection{Characterization of grain boundaries after micromechanical testing}

Micro-mechanical testing was conducted to understand the mechanical behaviour of the oxidized grain boundaries under the external-loading and, in particular, the stress required to fracture them. After the micromechanical testing, the fractured grain boundaries containing ICs were extracted by FIB from the microcantilevers and analysed by HAADF and EELS. The HAADF image in Fig. 4a shows that the upper carbide has started dissolving, releasing $\mathrm{Cr}$ to the oxide, and the matrix around both ICs was severely oxidized, which is consistent to that observed in Fig. 3a. Further observation reveals that the cracks preferentially propagated along the matrix-oxide interfaces and terminated at the end of the oxide. The EELS elemental qualitative maps show that the oxide around the upper carbide was enriched in $\mathrm{Cr}$ and $\mathrm{Fe}$, and depleted in $\mathrm{Ni}$, while the oxide around the bottom carbide was enriched in 
$\mathrm{Cr}$, and depleted in $\mathrm{Fe}$ and $\mathrm{Ni}$, which is similar to that observed in Fig. 3a. The different chemical composition in the oxides formed around the upper and bottom carbides could also be explained by the different oxidation times [39]. An EELS line-scan was also conducted to see the quantitative distribution of chemical composition across the upper IC. As shown in Fig. 4b, a gradient in $\mathrm{Cr}$ composition also existed in the oxide surrounding the upper carbide. The overlap between the IC and surrounding oxide was also observed, as marked in Fig. 4b

It is worth noting that there is a semi-continuous layer of Ni-rich precipitates around the IC. Similar results were also reported in the literature [20,33], and the authors attributed the formation of Ni-rich precipitates to the expulsion of solute atoms in metallic form during the process of selective oxidation. This theory can also be used to explain the observation in the current study, since the corrosion potential is also around the equilibrium of $\mathrm{Ni} / \mathrm{NiO}$ and the $\mathrm{Ni}$ is nobler than the other alloying elements $(\mathrm{Cr}$ and $\mathrm{Fe})$. The effect of this semi-continuous Ni-rich precipitates on the intergranular oxidation is still unclear, although it will disappear once water contacts it [4].

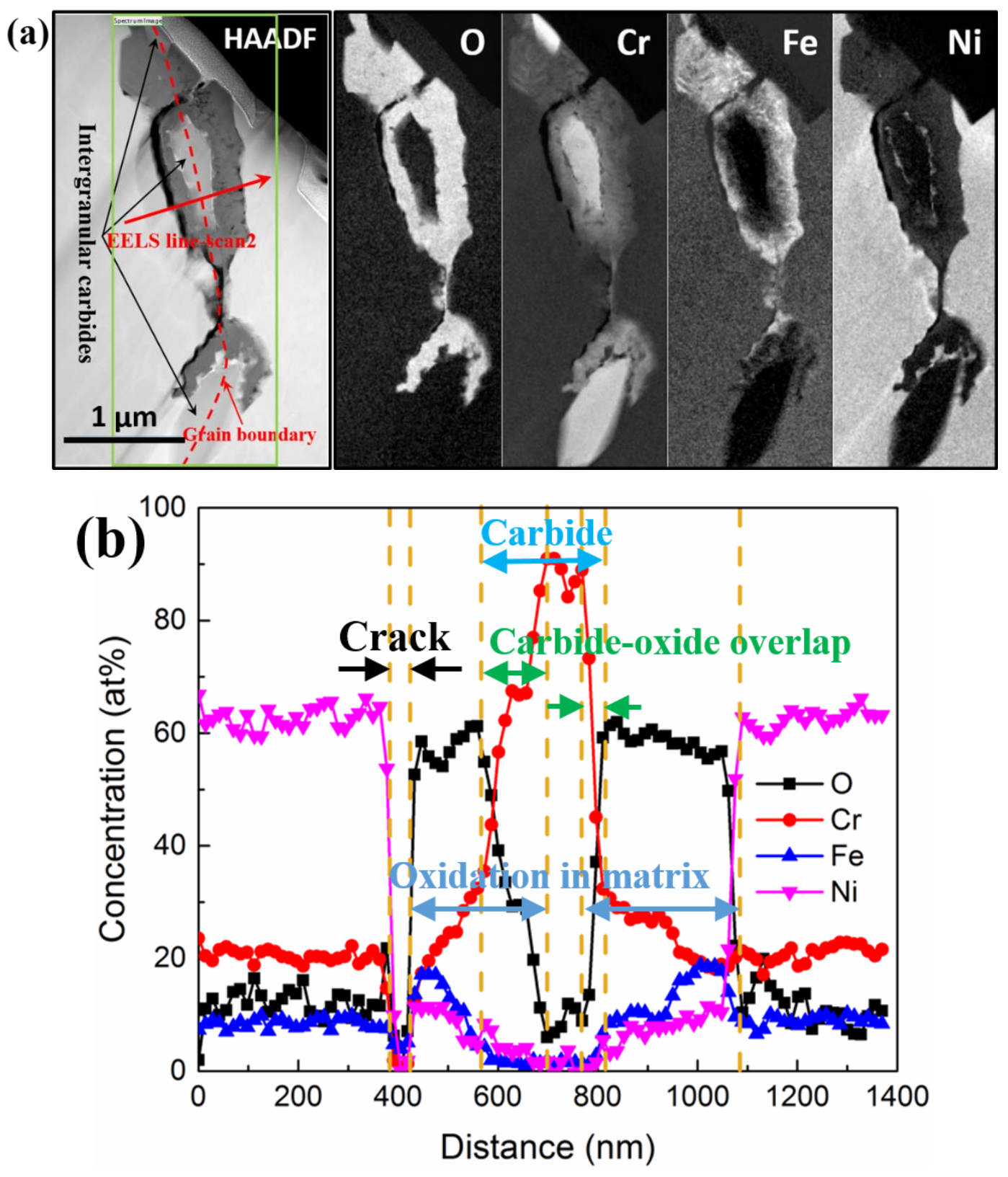


Fig. 4. (a) HAADF image with indication to the EELS line-scan2 location and related EELS elemental qualitative maps; (b) quantitative EELS line-scan across the IC.

\subsection{Porosity of the oxide-metal matrix interface}

Fig. 5a shows the HAADF image of an oxidized grain boundary at higher resolution compared to Fig. 3a. Multiple regions of lower contrast than the oxide and metal matrix were observed at the oxidematrix interfaces (marked by red arrows). The contrast generated by the scattered electrons in a HAADF image is proportional to atomic number variations, assuming a constant thickness and density. Darker regions correspond to regions of low atomic number $Z$ and brighter regions of higher atomic number. $\mathrm{O}(Z=8)$ for instance has lower atomic numbers than $\mathrm{Cr}(Z=24)$, $\mathrm{Ni}(Z=28)$, and $\mathrm{Fe}(Z=$ $26)$, which aligns with the darker appearance observed for the oxide compared with the metal matrix in Fig. 5a. However, from the HAADF image alone it is impossible to determine whether this contrast is mainly associated with changes in $Z$ or due to density variations (porosity). Before any final conclusions can be drawn the cause of the darker regions must be clarified.

The relative HAADF image intensity $I_{H A A D F}$ in a HAADF image is approximately proportional to $\mathrm{Z}^{2}$, with $\mathrm{Z}$ being the atomic number $\left(I_{H A A D F} \sim \mathrm{Z}^{2}\right)$. As a result, if the HAADF image contrast between two regions only originated from different atomic numbers, then $I_{H A A D F}(1) / I_{H A A D F}(2)$ should be equal to $Z^{2}(1) / Z^{2}(2)$. In addition, by comparing the ratios between the HAADF image intensity and the atomic number for the two regions, the origin of the contrast (or density variation) can be inferred. A I IAADF line profile was drawn across a region of interest marked in Fig. 5a. The average intensities of the matrix $\left(I_{\text {HAADF }}(\right.$ matrix $\left.)=670000\right)$ and dark region $\left(I_{\text {HAADF }}(\right.$ dark $\left.)=150000\right)$ were obtained $($ shown in Fig. 5c). By using the weighted atomic number average $(\mathrm{Z})$ based on the local atomic percentages of each region, $63 \% \mathrm{Ni}, 19 \% \mathrm{Cr}, 8 \% \mathrm{Fe}$ and $10 \% \mathrm{O}$ for the matrix and $9 \% \mathrm{Ni}, 12 \% \mathrm{Cr}, 19 \% \mathrm{Fe}$ and $60 \%$ $\mathrm{O}$ for the dark region, it is possible to show that the intensity ratio $\left(I_{\text {HAADF }}\right.$ (matrix)/ $I_{\text {HAADF }}($ dark $)=$ $4.47)$ was much greater than the atomic number ratio $\left(Z^{2}\right.$ (matrix)/ $Z^{2}($ dark $\left.)=2.76\right)$. Consequently, the contrast at the oxide-matrix interface was associated with a local decrease in thickness/density and, therefore, greater porosity in the dark region (see Fig. 5a), when compared with the surrounding metal matrix. The same procedure was repeated at different regions, proving many of the dark regions at the oxide-matrix interfaces to be porosities, as marked by the red arrows in Fig. 5a.

During the HAADF imaging, middle angle annular dark field (MAADF) image was collected simultaneously. Since the MAADF image is very sensitive to the crystallographic orientation of the examined specimen, features with different crystallographic orientations can be highlighted by different image contrast. As shown in Fig. 5b, the different image intensities between the oxide and metal matrix revealed that the oxide and the metal matrix appeared to have different crystallographic orientations, which might explain the preferential distribution of porosities at the oxide-matrix interfaces. Further observation reveals that the image intensity in the oxide was not uniform, indicating that the oxide was composed of many nano-crystallites. Similar results were also reported by Burke et al. [40]. 

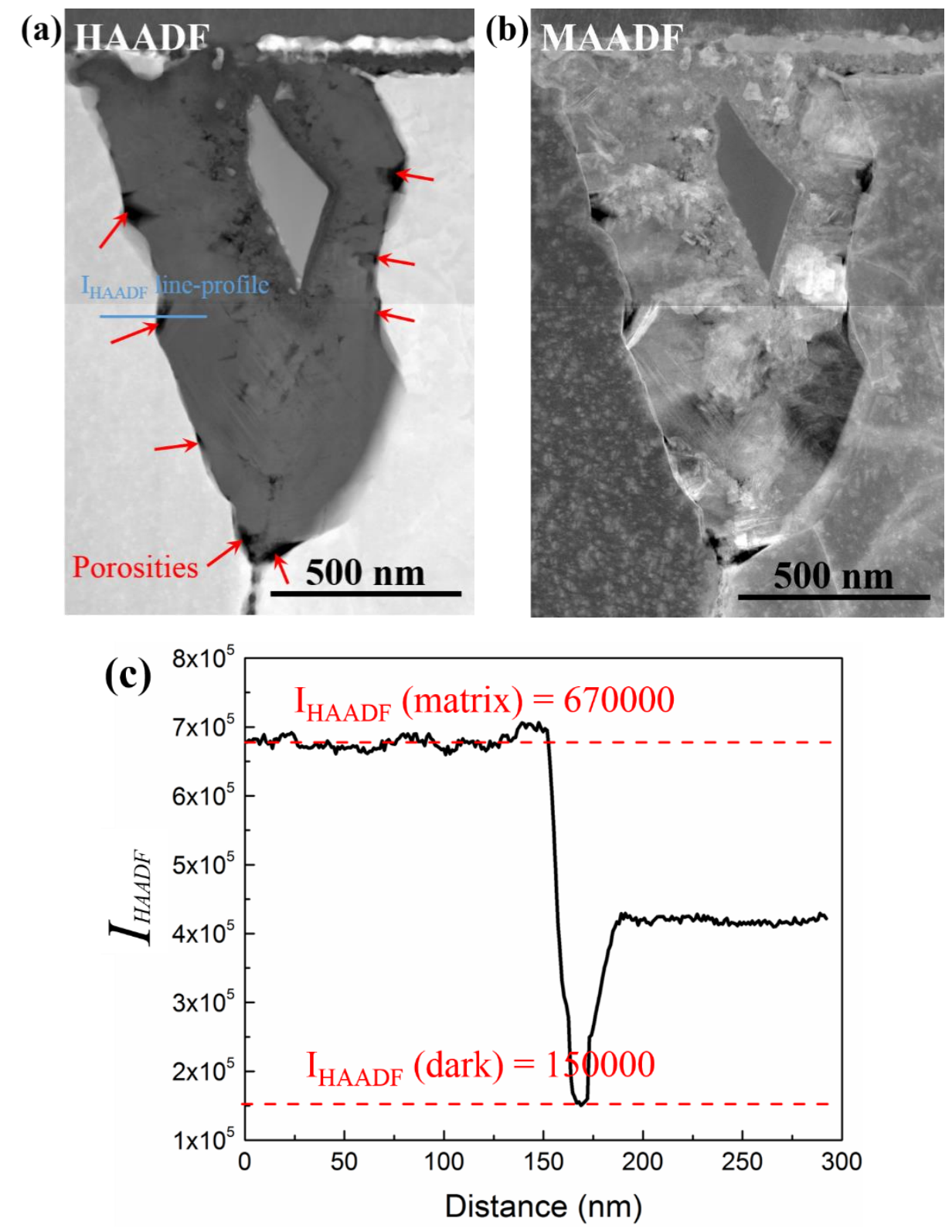

Fig. 5. (a) HAADF image showing the existence of porosities at the oxide-matrix interfaces; (b) MAADF image showing the oxide around the IC is composed of nano-crystallites; (c) HAADF image intensity line-profile.

\section{Discussion}

\subsection{The rate-limited process during intergranular oxidation}

The intergranular oxidation in all examined grain boundaries terminated at regions surrounding ICs. If the grain boundary region with ICs $(\sim 30 \%)$ is not more resistant to oxidation than the region without ICs $(\sim 70 \%)$, it is statistically more possible to observe the intergranular oxidation terminating at the region without ICs. This was not the case in any of the samples we analysed and it is sensible to assume that the ICs can decrease the intergranular oxidation rate locally and the oxidation within these regions can be the rate-limiting process. A fast oxidation rate in the $\mathrm{Cr}$ depleted grain boundary region where it is free of ICs can be expected since Cr-depletion has been reported to significantly enhance oxidation rate $[34,41,42]$. Although the rate-limiting process of intergranular oxidation was believed to be the oxidation in regions around ICs, it did not mean that the intragranular oxidation rate away from the 
ICs was lower than the grain boundaries free of ICs. On the contrary, the matrix around the ICs appeared to be preferentially oxidized, with oxides in these regions being much denser (see Figs. 3a and $4 \mathrm{a}$ ). However, compared to the $\mathrm{Cr}$-depleted grain boundary without carbides, the content of $\mathrm{Cr}$ in the region surrounding ICs was higher (see Fig. 2e), which should have resulted in lower oxidation rate but not preferential oxidation. As a result, there must be some other factors contributing to the preferential oxidation. Based on the results described above, one of the most plausible factors might be the accumulation of dislocations surrounding ICs (see Fig. 2d). Lozano-Perez et al. [43] observed preferential oxidation along the deformation bands, with similar results also being reported by Terachi et al. [27]. These authors believed that the deformation-induced defects can act as fast diffusion paths for oxygen and metallic elements, resulting in faster oxidation rates. A more detailed explanation about this topic has been reported by Langelier et al. [33]. Consequently, although no obvious Cr-depletion existed in the matrix surrounding ICs, the existence of a large number of defects could still result in faster oxidation rates. As shown in Fig. 2d, the shape of the preferential deformation zone around ICs was also similar to the shape of the oxide, which further supports the hypothesis proposed above. As shown in Fig. 5, nanopores are observed at the oxide-metal interfaces. The under-focused TEM image (see the supplementary Fig. S1) confirms the existence of nanopores at the oxide-metal interfaces. Furthermore, nanopores are also observed in the thick oxide surrounding the ICs, although the density appears to be lower than that at the oxide-metal interface. The existence of nanopores can act as shortcircuits for water ingress, resulting in enhanced oxidation.

\subsection{The carbide dissolution and $\mathrm{Cr}$ outward diffusion}

Many mechanisms have been proposed to explain the mitigating effect of ICs on SCC in Alloy 600 without cold-working [2, 7, 14, 19-21, 38]. Among these mechanisms, the "Cr reservoir" mechanism appeared to be one of the most plausible mechanisms according to the experimental observations. The "Cr reservoir" mechanism considers that the Cr-rich ICs can provide $\mathrm{Cr}$ to form more compact $\mathrm{Cr}$-rich oxide and then decrease the intergranular oxidation rate [7, 14, 19, 38]. Although the oxide formed around the ICs examined in the current study was also enriched in $\mathrm{Cr}$, the origin of $\mathrm{Cr}$ in the $\mathrm{Cr}$-rich oxide remains unclear. There were mainly two possible sources: one being the surrounding matrix and the other the carbides. Since no obvious Cr-depletion was detected in the matrix close to the oxide (see Fig. 2e), the only possible origin for the increased $\mathrm{Cr}$ within the oxide was from the ICs. This hypothesis appeared sensible due to the existence of a $\mathrm{Cr}$ composition gradient, decreasing from the original matrix-carbide interface towards the matrix. It is worth noting that although no obvious $\mathrm{Cr}$ depletion was detected in the matrix surrounding the oxide, pipe diffusion of a minor content of $\mathrm{Cr}$ along the matrix dislocations down to the oxide was still possible. In addition, the rapid $\mathrm{Cr}$ diffusion from the grain boundary ahead of the oxidation front was also possible. However, considering the obvious $\mathrm{Cr}$ enrichment in the oxide surrounding the ICs, the main contributor is likely to be the outward diffusion of $\mathrm{Cr}$ from the ICs. As a result, the observation of $\mathrm{Cr}$ enrichment in the oxidized matrix surrounding the ICs appeared to support the "Cr reservoir" mechanism.

Although the oxides surrounding the ICs were enriched in $\mathrm{Cr}$, the oxides in these regions were thicker than that formed at the grain boundaries without carbides (see Figs. 3a and 4a). As discussed above, the formation of dense oxide around the ICs was caused by the preferential accumulation of dislocations around the ICs during cold-working. Although the carbide dissolution-induced outward diffusion of $\mathrm{Cr}$ could lead to the formation of more compact Cr-rich oxides, such oxides would only be able to restrain the diffusion of oxygen through them, resulting in a lower oxidation rate in the direction along the grain boundary (a lower intergranular oxidation rate). Due to the existence of porosities at the oxide-metal matrix interfaces (see Fig. 5a), oxygen could still diffuse along the porous 
interfaces and then oxidize the surrounding matrix containing a higher content of dislocations (preferential accumulation of dislocations during cold-working).

Persaud et al. [20] observed a severe dissolution of ICs in the oxidized grain boundaries after exposure to hydrogenated steam at $480^{\circ} \mathrm{C}$, where the authors proposed an "oxygen sink" mechanism to explain the IC mitigating effect. Similar results were also reported by Bertali et al. [31]. The "oxygen sink" mechanism assumed the ICs to be more readily oxidized by the inward diffusion of oxygen, impeding further intergranular oxygen diffusion [20]. In the current study, the carbide dissolution was also observed, although the extent was much lower than that observed in [20,31]. This difference might be mainly due to the different experimental conditions (hydrogenated steam at $480^{\circ} \mathrm{C}$ vs. hydrogenated water at $340^{\circ} \mathrm{C}$ ). Compared with the carbide dissolution, the matrix surrounding the ICs appeared to be more readily oxidized due to the dislocation accumulation. Hence, it might be sensible to postulate that the preferential deformed matrix surrounding the ICs could also work as an "oxygen sink" and reduce the oxidation rate along the grain boundaries.

\subsection{The fracture of oxidized grain boundaries}

After performing micromechanical testing on oxidized grain boundaries, Dohr et al. [35] observed that all oxidized grain boundaries were fractured, with all cracks terminating at the end of the intergranular oxide. Hence, the authors concluded that the intergranular oxidation is prerequisite for SCC crack growth to occur. Therefore, any factors that effect intergranular oxidation would also effect SCC crack growth. ICs were widely believed to have a mitigating effect on SCC, which was mainly attributed to its inhibiting effect on intergranular oxidation [7, 14, 19, 38], although its mechanical effect on crack propagation was also reported $[2,19,21]$. The inhibiting effect of ICs on intergranular oxidation was also discussed in this work. As to the mechanical effect of ICs on crack propagation, no straightforward conclusions could be drawn just based on the results reported in the current study. However, by comparing to results reported in the literature [2, 19,21], several conclusions might be drawn. For example, the "crack tip blunting" mechanism [21] appeared to be not applicable in this case since the cracks that occurred in this study were not along oxide-carbide interfaces, implying that ICs could not have been functioning as dislocation sources to blunt the crack tips. The "crack path diversion" mechanism $[2,19]$ seems to still be applicable since the crack growth paths observed in this study also show a curved shape. Such paths could increase the total crack length and decrease the effective stress, resulting in the decline of SCC crack growth.

Although the fracturing of oxidized grain boundaries along oxide-matrix interfaces after micromechanical testing has been reported in $[2,35]$, due to the lack of high-resolution analysis, the underlying reasons could not be well explained. According to our analysis of HAADF images (see Fig. 5a), the preferential cracking along the oxide-matrix interfaces was mainly due to the existence of nanoporosities at these interfaces. The existence of nanoporosities at the oxide-matrix interfaces would decrease the mechanical strength of these phase boundaries, which would therefore be more easily cracked under external loading. The formation of nanoporosities at the oxide-matrix interface might be attributed to the different lattice parameters of the metal matrix compared to the oxides, which would inevitably introduce defects at the phase boundaries during the process of oxidation. Terachi et al. [44] reported that the lack of $\mathrm{Cr}$ (lower than 28\%at.) will lead to the formation of porous spinel oxides due to the lack of $\mathrm{Cr}^{3+}$ cations. Since the $\mathrm{Cr}$ content in the black spots at the oxide-metal interface was lower than $28 \%$ at., the lack of $\mathrm{Cr}^{3+}$ cations might also be a possible reason contributing to the porous oxide-metal interface. 
In the study of SCC crack growth in a $20 \%$ cold-worked Alloy 600 after exposure to PWR primary water at $360^{\circ} \mathrm{C}$ [4], both the carbide dissolution and enhanced oxidation around the ICs were not observed. In addition, the crack was observed to propagate along the carbide-oxide interface but not the metal-oxide interface. These differences might be mainly due to the different oxidation time in these two situations. In the current study, the grain boundaries had been exposed to the PWR water for $2000 \mathrm{~h}$ before they were mechanically fractured, while the carbide observed in [4] was around $2 \mu \mathrm{m}$ away from the SCC crack tip (shorter exposure). As a result, the results obtained in the current study might be more similar to the situation of crack initiation, during which the grain boundaries should have suffered very long time of oxidation before the crack to initiate.

\section{Conclusions}

1. Prior cold-working caused increased plastic deformation in the metal matrix surrounding ICs. The metal matrix was more readily oxidized than the grain boundary region free of ICs during the process of intergranular oxidation.

2. The rate-limiting process of intergranular oxidation is proposed to be the oxidation within the region around ICs. The more readily oxidation in the metal matrix surrounding ICs and the outward diffusion of $\mathrm{Cr}$ from ICs into the oxide surrounding them worked together to inhibit the oxidation along the grain boundaries.

3. Porosities were preferentially distributed along the oxide-metal matrix interfaces after intergranular oxidation. After the micromechanical tests, all cracks propagated along the oxide-metal matrix interfaces and terminated at the end of the intergranular oxide.

4. The crack growth along oxide-metal matrix interfaces diverted the crack from straight path to curved path. This is supposed to decrease the CGR locally through increasing the total crack length and decreasing the effective applied stress locally.

\section{Acknowledgements}

The authors would like to thank INSS (Japan) for providing the sample used in this study. Charles Fletcher and Koji Arioka are acknowledged for useful discussion. Zhao Shen is grateful to China Scholarship Council (CSC) for providing financial support to his PhD studentship. The EPSRC (EP/K040375/1, EP/N010868/1 and EP/R009392/1) grants are also acknowledged for funding this research.

\section{References}

[1] H. Coriou, L. Crall, Y. L. Gall, S. Vettier, 3rd Metallurgy Conf. on Corrosion, Saclay (Amsterdam, The Netherlands: North Holland Publishing Co., 1959), 1960, pp. 161-169.

[2] H. Dugdale, D.E. Armstrong, E. Tarleton, S.G. Roberts, S. Lozano-Perez. How oxidized grain boundaries fail. Acta Materialia, 61(2013): 4707-4713.

[3] W. Bamford, J. Hall, "Cracking of alloy 600 nozzles and welds in PWRs: review of cracking events and repair service experience.", in: Proceedings of the 12th Int'l Conf. on Environmental Degradation of Materials in Nuclear Power Systems - Water Reactor, Salt Lake City, UT, 2005, p. 959.

[4] Z. Shen, J. Liu, K. Arioka, S. Lozano-Perez. On the role of intergranular carbides on improving the stress corrosion cracking resistance in a cold-worked alloy 600. Journal of Nuclear Materials, 514(2019): 50-55. 
[5] R. Morris, N. Lewis, D.S. Morton. 3D analysis of surface treatment effects on the oxidation of grain boundaries in Alloy 600. In Proceedings of the 16th International Symposium on Environmental Degradation of Materials in Nuclear Power Systems--Water Reactors, (NACE, 2014).

[6] G. Bertali, F. Scenini, M. G. Burke. Advanced microstructural characterization of the intergranular oxidation of Alloy 600. Corrosion Science, 100 (2015): 474-483.

[7] G. Bertali, F. Scenini, M.G. Burke. The intergranular oxidation susceptibility of thermally-treated Alloy 600. Corrosion Science, 114(2017): 112-122.

[8] H.A. Domian, R.H. Emanuelson, L.W. Sarver, G.J. Theus, L. Katz. Effect of microstructure on stress corrosion cracking of Alloy 600 in high purity water. Corrosion, 33(1977): 26-38.

[9] N. Pessall, G.P. Airey, B.P. Lingenfelter. The influence of thermal treatment on the SCC behavior of Inconel alloy 600 at controlled potentials in $10 \%$ caustic soda solutions at 315 C. Corrosion, 35(1979): 100-107.

[10] G. Economy, R.J. Jacko, F.W. Pement. IGSCC behavior of Alloy 600 steam generator tubing in water or steam tests above $360^{\circ}$ C. Corrosion, 43(1987): 727-734.

[11] J.L. Hertzberg, G.S. Was. Isolation of carbon and grain boundary carbide effects on the creep and intergranular stress corrosion cracking behavior of $\mathrm{Ni}-16 \mathrm{Cr}-9 \mathrm{Fe}-\mathrm{xC}$ alloys in $360 \mathrm{C}$ primary water. Metallurgical and Materials Transactions A, 29(1998): 1035-1046.

[12] B. Alexandreanu, B. Capell, G.S. Was. Combined effect of special grain boundaries and grain boundary carbides on IGSCC of $\mathrm{Ni}-16 \mathrm{Cr}-9 \mathrm{Fe}-\mathrm{xC}$ alloys. Materials Science and Engineering: A, 300(2001): 94-104.

[13] R.B. Rebak, Z. Xia, Z. Szklarska-Smialowska. Effects of carbides on susceptibility of alloy 600 to stress corrosion cracking in high-temperature water. Corrosion, 49(1993): 867-876.

[14] L.E. Thomas, S.M. Bruemmer. High-resolution characterization of intergranular attack and stress corrosion cracking of Alloy 600 in high-temperature primary water. Corrosion, 56(2000): 572-587.

[15] M. Sennour, P. Laghoutaris, C. Guerre, R. Molins. Advanced TEM characterization of stress corrosion cracking of Alloy 600 in pressurized water reactor primary water environment. Journal of Nuclear Materials, 393(2009): 254-266.

[16] Y.S. Lim, H.P. Kim, S.S. Hwang. Microstructural characterization on intergranular stress corrosion cracking of Alloy 600 in PWR primary water environment. Journal of Nuclear Materials, 440(2013): 46-54.

[17] K. Arioka, T. Yamada, T. Terachi, G. Chiba. Influence of carbide precipitation and rolling direction on intergranular stress corrosion cracking of austenitic stainless steels in hydrogenated hightemperature water. Corrosion, 62(2006): 568-575.

[18] K. Arioka, T. Yamada, T. Terachi, R.W. Staehle. Intergranular stress corrosion cracking behavior of austenitic stainless steels in hydrogenated high-temperature water. Corrosion, 62(2006): 74-83.

[19] G.S. Was, K. Lian. Role of carbides in stress corrosion cracking resistance of alloy 600 and controlled-purity Ni-16\% Cr-9\% Fe in primary water at 360 C. Corrosion, 54(1998): 675-688. 
[20] S.Y. Persaud, A. Korinek, J. Huang, G.A. Botton, R.C. Newman. Internal oxidation of Alloy 600 exposed to hydrogenated steam and the beneficial effects of thermal treatment. Corrosion Science, 86(2014): 108-122.

[21] S.M. Bruemmer, L.A. Charlot, C.H. Henager Jr. Microstructure and microdeformation effects on IGSCC of Alloy 600 steam generator tubing. Corrosion, 44(1988): 782-788.

[22] J. Hou, Q. J. Peng, Z. P. Lu, T. Shoji, J. Q. Wang, E-H. Han, W. Ke. Effects of cold working degrees on grain boundary characters and strain concentration at grain boundaries in Alloy 600. Corrosion Science, 53 (2011): 1137-1142.

[23] Z. Lu, T. Shoji, S. Yamazaki, K. Ogawa. Characterization of microstructure, local deformation and microchemistry in Alloy 600 heat-affected zone and stress corrosion cracking in high temperature water. Corrosion Science, 58(2012): 211-228.

[24] E.A. West, G. S. Was. Strain incompatibilities and their role in intergranular cracking of irradiated 316L stainless steel. Journal of Nuclear Materials, 441(2013): 623-632.

[25] Z. Shen, K. Arioka, S. Lozano-Perez. A mechanistic study of SCC in Alloy 600 through highresolution characterization. Corrosion Science, 132(2018): 244-259.

[26] S. Lozano-Perez, T. Yamada, T. Terachi, M. Schröder, C. A. English, G. D. W. Smith, C. R. M. Grovenor, B. L. Eyre. Multi-scale characterization of stress corrosion cracking of cold-worked stainless steels and the influence of Cr content. Acta Materialia, 57(2009): 5361-5381.

[27] T. Terachi, T. Yamada, T. Miyamoto, K. Arioka. SCC growth behaviors of austenitic stainless steels in simulated PWR primary water. Journal of Nuclear Materials, 426(2012): 59-70.

[28] S.M. Bruemmer, M. J. Olszta, M. B. Toloczko, L. E. Thomas. "High-resolution characterizations of grain boundary damage and stress corrosion cracks in cold-rolled alloy 690." In Proceedings of the 15th International Conference on Environmental Degradation of Materials in Nuclear Power Systems-Water Reactors, pp. 301-314. Springer, Cham, 2011.

[29] M.B. Toloczko, M.J. Olszta, S.M. Bruemmer. "One dimensional cold rolling effects on stress corrosion crack growth in alloy 690 tubing and plate materials." In Proceedings of the 15th International Conference on Environmental Degradation of Materials in Nuclear Power SystemsWater Reactors, pp. 91-107. Springer, Cham, 2011.

[30] W. Kuang, G.S. Was. The effects of grain boundary carbide density and strain rate on the stress corrosion cracking behavior of cold rolled Alloy 690. Corrosion Science, 97(2015): 107-114.

[31] G. Bertali, F. Scenini, M. G. Burke. "Solution-annealed and thermally-treated Alloy 600 preferential intergranular oxidation: a comparison." In Proceedings of the 17th International Symposium on Environmental Degradation of Materials in Nuclear Power Systems-Water Reactors,TMS/AIME, 2015.

[32] J.J. Kai, C.H. Tsai, G.P. Yu. The IGSCC, sensitization, and microstructure study of Alloys 600 and 690. Nucl. Eng. Des., 144 (1993): 449-457.

[33] B. Langelier, S. Y. Persaud, R. C. Newman, G. A. Botton. An atom probe tomography study of internal oxidation processes in Alloy 600. Acta Materialia 109 (2016): 55-68. 
[34] K. Arioka, T. Yamada, T. Miyamoto, M. Aoki, Intergranular stress corrosion cracking growth behavior of $\mathrm{Ni}-\mathrm{Cr}-\mathrm{Fe}$ alloys in pressurized water reactor primary water. Corrosion. 70(2014) 695-707.

[35] J. Dohr, D.E. Armstrong, E. Tarleton, T. Couvant, S. Lozano-Perez. The influence of surface oxides on the mechanical response of oxidized grain boundaries. Thin Solid Films, 632(2017): 17-22.

[36] S. Lozano-Perez. A guide on FIB preparation of samples containing stress corrosion crack tips for TEM and atom-probe analysis. Micron, 39(2008): 320-328.

[37] M. Meisnar, A. Vilalta-Clemente, A. Gholinia, M. Moody, A.J. Wilkinson, N. Huin, S. LozanoPerez. Using transmission Kikuchi diffraction to study intergranular stress corrosion cracking in type 316 stainless steels. Micron, 75(2015): 1-10.

[38] J. Panter, B. Viguier, J.M. Cloué, M. Foucault, P. Combrade, E. Andrieu. Influence of oxide films on primary water stress corrosion cracking initiation of alloy 600. Journal of Nuclear Materials, 348(2006): 213-221.

[39] A. Atkinson, Transport processes during the growth of oxide films at elevated temperature, Rev. Mod. Phys. 57(1985): 437-470.

[40] M.G. Burke, W.C. Moshier, G.J.C. Carpenter, M.W. Phaneuf. Characterization of Intergranular Fracture Surfaces in a Ni-Cr-Fe Alloy using SEM, FIB and AEM Techniques. Microscopy and Microanalysis, 10(2004): 1140-1141.

[41] B.W. Bennett, H.W. Pickering. Effect of grain boundary structure on sensitization and corrosion of stainless steel. Metallurgical Transactions A, 18(1991): 1117-1124.

[42] Z. Shen, M. Meisnar, K. Arioka, S. Lozano-Perez. Mechanistic understanding of the temperature dependence of crack growth rate in alloy 600 and 316 stainless steel through high-resolution characterization. Acta Materialia, 165(2019): 73-86.

[43] S. Lozano-Perez, K. Kruska, I. Iyengar, T. Terachi, T. Yamada. The role of cold work and applied stress on surface oxidation of 304 stainless steel. Corrosion Science, 56(2012): 78-85.

[44] T. Terachi, T. Yamada, T. Miyamoto, K. Arioka, Role of grain boundary oxidation on PWSCC initiation influence of chemical compositions and stress. INSS Journal, 18(2011) 137-151. 